\title{
A study of mortality among 14730 male workers in 12 Norwegian ferroalloy plants: cohort characteristics and the main causes of death
}

\author{
Ånund Hobbesland, Helge Kjuus, Dag S Thelle
}

\begin{abstract}
Objectives-Concern about the health hazards of exposure to workers in the ferroalloy industry has initiated this historical cohort study. The aim was to examine the mortality pattern among male employees in 12 Norwegian ferroalloy plants.

Methods-All men employed for at least six months who started their first employment during 1933-91 were eligible for the cohort. Deaths observed during 1962-90 were compared with expected figures calculated from national mortalities. Internal comparisons of rates were performed by Poisson regression analysis. The final cohort comprised 14730 male employees who were observed for 288886 person-years.
\end{abstract}

Results-Mortality from all causes of death was slightly increased (3390 deaths, standardised mortality ratio (SMR) 1.08, $95 \%$ confidence interval (95\% CI) $1 \cdot 04-1 \cdot 11)$. Regression analysis of total mortality showed a significant negative trend for the rate ratios with increasing duration of employment. An increased mortality was found among employees in urban plants compared with employees in rural plants (rate ratio (RR) $1 \cdot 21,95 \%$ CI 1.13-1.29). Excess deaths from cancer (SMR 1.11) and sudden death (SMR 1.47) were found among employees with at least three years of employment. Mortality from accidents, poisonings, and violence was increased among all employees (SMR 1.28). Excess deaths from this cause were however only found for the time after the end of employment in this industry and not during employment (SMR 0.90).

Conclusions-The increased mortality from cancer and sudden death could be related to work exposures, at least in subgroups, and these results warrant further studies. The excess deaths from accidents, poisonings, and violence were probably not related to work exposures. The mortality results for short term workers and other information indicate that systematic errors contribute to the increased overall mortality.

(Occup Environ Med 1996;53:540-546)

Keywords: ferroalloy; mortality; employment status
By definition, ferroalloys include metals alloyed with iron such as ferrosilicon ( $\mathrm{FeSi}$ ), ferromanganese (FeMn), ferrochromium $(\mathrm{FeCr})$, and ferrovanadium ( $\mathrm{FeV})$. Traditionally, however, other metal products such as silicon metal ( $\mathrm{Si}-\mathrm{met}$ ) containing $99 \%$ elementary silicon and silicon manganese alloy ( $\mathrm{SiMn}$ ) have also been included among the ferroalloys. The ferroalloys are used in iron foundries and steelworks to remove oxygen and give the metal special properties. During several decades the Norwegian production of ferroalloys has been one of the largest in western Europe. Most of the ferroalloy plants are situated by the coast from the south eastern to the northern part of Norway.

Most of the ferroalloys are produced by similar processes and equipment. Raw materials are weighed, mixed, and put into the top of tall cylindrical furnaces. The high temperature in the furnaces (about $1500^{\circ} \mathrm{C}$ ) fuses the materials and the chemical process removes oxygen from the metals by a reaction between oxygen and carbon, leading to discharge of carbon monoxide and carbon dioxide. The reduction materials most commonly used are coke and coal (anthracite). The furnaces usually have three Søderberg electrodes encapsulated in a steel casing which serves as an electrical conductor. Electrode paste made of calcinated anthracite and a binder of tar and pitch are put into the electrodes at the top. The liquid metals-for example, iron and silicon-are drained out at the bottom of the furnace and are further cooled, crushed, and packed.

Thus, the workers in a ferroalloy plant are exposed to a mixture of gases, fumes, and dusts and to physical factors such as heat and electromagnetic fields. This has brought up concern about the health hazards of the exposures in this industry. Previously, three studies of cancer incidence and total mortality among employees in a total of seven Norwegian ferroalloy plants have been performed. ${ }^{1-3}$ The overall mortality was not increased in any of these studies. However, none of the studies analysed cause specific mortality. We have therefore performed a new historical cohort study of the mortality pattern among employees in a total of 12 Norwegian ferroalloy plants, comprising both the seven original and five other plants. The aim was to examine the possible effects from work exposure on the mortality pattern. 


\section{Material and methods}

Altogether 14 Norwegian plants produced ferroalloys before 1990. Nine of the plants started production before 1930 (the first one in 1898) and five during the period 1962-74. One plant closed down in 1987. Ten plants produced $\mathrm{FeSi}$ and $\mathrm{Si}$-met as their main products and four plants produced mainly FeMn and SiMn. Also, two of the FeSi/Si-met plants previously produced $\mathrm{FeCr}$, two plants calcium carbide, one plant $\mathrm{FeV}$, and one plant electrode paste. Three of the FeMn/SiMn plants have also produced $\mathrm{FeSi}$, and one plant $\mathrm{FeCr}$ and several other alloys in smaller amounts.

\section{EXPOSURE FACTORS AND HEALTH HAZARDS Chrystalline silica}

Chrystalline silica $\left(\mathrm{SiO}_{2}\right)$ is a raw material in the production of $\mathrm{FeSi}, \mathrm{SiMn}$, and $\mathrm{Si}$-met. In particular workers engaged in transport, crushing, and filling the furnaces have been exposed to chrystalline silica. Exposure to chrystalline silica implies a risk of developing silicosis, ${ }^{4}$ and there is limited evidence that chrystalline silica is also carcinogenic to humans. ${ }^{56}$

\section{Manganese dioxide}

Manganese dioxide $\left(\mathrm{MnO}_{2}\right)$ and manganese oxide $(\mathrm{MnO})$ are major constituents of the manganese ore used as a raw material in production of FeMn and SiMn. Exposure to $\mathrm{MnO}_{2}$ has been reported to increase the prevalence of acute bronchitis and respiratory tract symptoms, ${ }^{7}$ to induce an inflammatory reaction in the respiratory tract, and decrease the resistance toward certain respiratory infections. $^{8}$

\section{Carbon monoxide}

Carbon monoxide (CO) is a byproduct in the furnace process. The risk of dying from an acute intoxication with $\mathrm{CO}$ is well known, but high exposure to $\mathrm{CO}$ is supposed to occur seldom in this industry. A few studies of long term effects of exposure to $\mathrm{CO}$ have indicated increased risks of cardiovascular morbidity and mortality. ${ }^{910}$ The risk is dependent upon the exposure intensity and seems to decline after the end of exposure. ${ }^{10}$

\section{Polycyclic aromatic hydrocarbons}

Polycyclic aromatic hydrocarbons (PAHs) are made by incomplete combustion of the electrodes and other carbonaceous material in the furnace. In particular work near the top of the electrodes may have involved exposure to PAHs. There is varying evidence that exposures to PAHs in different industries (aluminium production, coke production) are responsible for the increased incidence of cancer in the respiratory tract and the bladder found among these workers. ${ }^{112}$ It has also been hypothesised that PAHs increase the risk of ischaemic heart disease. ${ }^{13}$

Asbestos

Until 1982 exposure to asbestos (mainly chrysotile asbestos) was usual, in particular for mechanics. Exposure to asbestos has for a long time been recognised as a cause of asbestosis, lung cancer, and malignant mesothelioma, and some studies have also indicated increased risk of cancers of the larynx and gastrointestinal tract. ${ }^{14}$

\section{Other exposure factors}

There are many other exposure factors in this industry with uncertain health hazards or with potential hazards only to smaller groups of workers. Some of these exposure factors are dust of coke and coal, amorphous silica, arsine, phosphine, $\mathrm{Cr}^{6+}$, dust from the metals produced, heat, electromagnetic fields, and shift work.

\section{EXPOSURE VARIABLE}

Knowledge about exposure of individual men did not exist, so the exposure variables had to be based on employment information (employment periods, work areas, and jobs). Evaluation of registered data clearly showed that job title information was inaccurate. So the only reliable information about a man's work was the employment periods and work area. Most of the work areas (departments) comprise workers with various jobs and varying exposures. Sporadic personal monitoring mainly of total dust exposure of workers in particular jobs had been performed during the past 10-20 years. The relevance of these data for assessment of average exposure for all workers within the departments was unknown and was not used for further exposure assessment. Thus, in this study duration of employment in the plant and in the various work areas (departments) have been used as proxies for true exposure information.

\section{COHORT}

The primary inclusion criteria was employment in any of the 14 eligible ferroalloy plants for at least six months excluding all employment periods shorter than three months. Only men employed for the first time after 1 January 1933 were elected to the cohort. The main source of information was manual employment records. Variables recorded were employee's name, birthdate, the 5-digit personal number, up to 10 employment periods, and smoking habits (from medical records).

The completeness of the subcohort from each plant was evaluated by calculating the numbers of employees starting and ending work in each plant each year. Numbers employed in each plant each year (including both men and women) were also calculated and compared with figures from other sources (yearbooks, etc). For most of the plants the agreement between these figures was good. But comparative figures were not available before 1960 in many plants. The figure shows an example of such a comparison. These procedures indicated that the data from two $\mathrm{FeSi}$ plants were incomplete. These were then excluded, leaving 12 plants in the study. The control procedures also led to restrictions of older recruitment periods (after 1 January 1933) for some of the remaining subcohorts to exclude periods where the employment infor- 


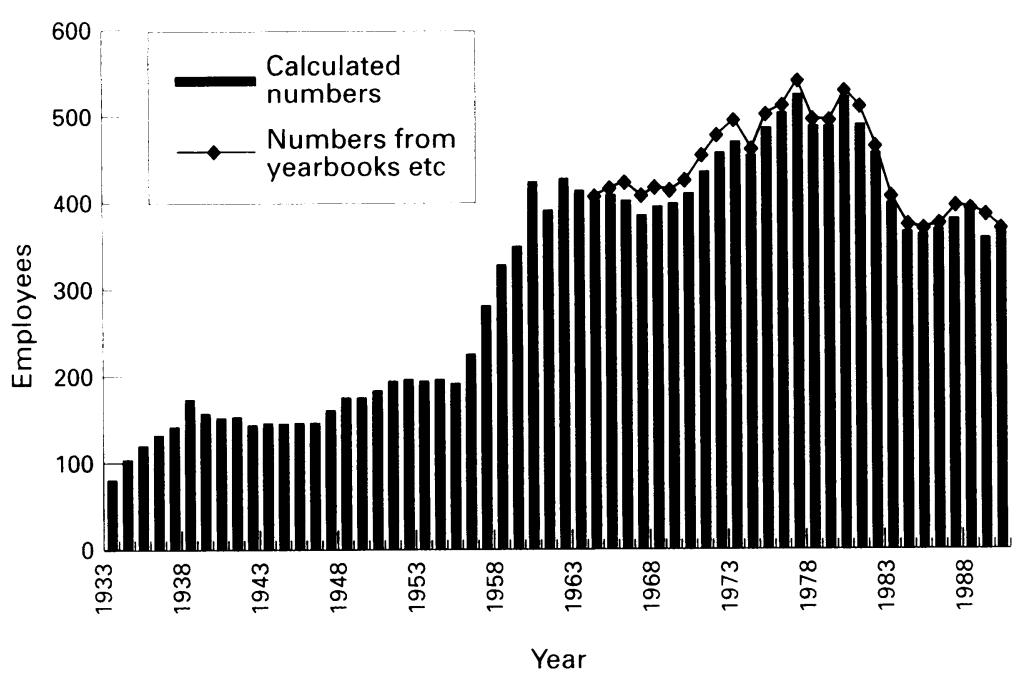

Numbers of employees in each year in one plant compared with numbers of employees in the same plant from yearbooks etc.

mation was obviously incomplete.

A control procedure with the personal number was performed by connecting the cohort to the official population register. In Norway, only people emigrated or dead before 1960 are lacking the 5-digit personal number. The vital data for these were sought individually starting from name and birth date. Information on individual cause of death and death date was supplied by linking the cohort to Statistics Norway (the national register for causes of death). The classification of causes of death follows the international classification of diseases (ICD). The seventh (ICD-7) to ninth (ICD-9) versions have been used successively. Only the underlying cause of death was registered and not contributory causes. The cause of death could not be traced for four men who were then not counted as dead.

Only men were included in the final cohort. Each man was followed up from the beginning of 1962 or if he was hired later, from the date of first employment until death (or emigration) or the end date of the study (31 December 1990) for those still alive and under observation. Altogether 467 men (3\%) were lost to follow up. Also, 162 men (1\%) were known to have died during the period 1953-61 and were thereby excluded (table 1 ). The number of men who were lost to follow up but actually died before 1953 was not investigated.

\section{ANALYSIS}

Two types of analyses have been performed. The first is a comparison of the observed numbers of deaths in the study population with expected numbers of deaths in the general population. The expected numbers were calculated from the 5-year age specific rates for each

Table 1 Formation of the male cohort of employees in 12 Norwegian ferroalloy plants

\begin{tabular}{lc}
\hline Primary cohort: & 18290 \\
Women: & 1326 \\
Men: & 16964 \\
Employed before 1933 & 1605 \\
Lost to follow up & 467 \\
Died in the period 1953-61 & 162 \\
Final cohort (men) & 14730 \\
\hline
\end{tabular}

year from 1962 to 1990 for the total Norwegian male population. Standardised mortality ratios (SMRs) were calculated for total and specific causes of death. The Epicure program package ${ }^{15}$ was used to create event time tables stratified by both fixed and time dependent variables. Analysis of mortality in time related categories of employment status (active and inactive person-time) was performed. ${ }^{16}$ Active person-time was defined as all person-time from the start of follow up until the end of the last employment (including periods off work before that time). Inactive persontime was defined as person-time after the end of the last employment. In these analyses the registered date of the end of the last employment $+0 \cdot 1$ year was used as a distinction between active and inactive person-time.

For all SMRs a $95 \%$ confidence interval $(95 \%$ CI $)$ was calculated by assuming a Poisson distribution of the observed numbers and assuming the expected numbers to be constants. For results with 100 or less cases exact $95 \%$ CIs were calculated from tabulated values of $95 \%$ CIs for a Poisson distributed variable. In situations with $>100$ cases approximate $95 \%$ CIs were calculated with the formula $\exp (\ln (S M R) \pm 1.96 \mathrm{SE})$ with $S E$ for $\ln (\mathrm{SMR})$ estimated to be $1 / \mathrm{D}^{1 / 2}$ where $\mathrm{D}$ is the number of deaths.'

The second way of analysis was internal comparisons of rates by Poisson regression analysis for grouped survival data (with the Amfit program in the Epicure program package). Only the default model (product additive excess model) was used. Confidence intervals (95\%) for risk ratios (RRs) and $P$ values for trend analysis were calculated by the program. Test for trend was performed by scoring the categories of a variable by their mean values in the final model and calculating the $\mathrm{P}$ value for the likelihood ratio test when the variable was withdrawn from the model. In the regression analysis of mortality from accidents, poisonings, and violence (tables 7 and 8), employment status was included in the model as it has been suggested to be appropriate to control for employment status when it is a time related confounder but not an intermediate variable (on the causal pathway between exposure and death). ${ }^{1 \times}$

In the analysis of mortality among workers in different departments the duration of work was only related to work in the actual department. Men who had been working in different departments were included in the analyses of mortality among employees in each of the actual departments.

Table 2 Some characteristics of the cohort of 14730 male workers in 12 Norwegian ferroalloy plants

\begin{tabular}{ll}
\hline Year at start of first employment $^{\star}$ & $1964(1940-86)$ \\
Age at start of first employment $(y)^{\star}$ & $25 \cdot 5(17 \cdot 2-53 \cdot 4)$ \\
Duration of total employment $(y)^{\star}$ & $5 \cdot 4(0 \cdot 7-35 \cdot 8)$ \\
Age at end of last employment $(y)^{\star}$ & $36 \cdot 8(20 \cdot 1-67 \cdot 0)$ \\
Year of death ${ }^{\star}$ & $1981(1965-90)$ \\
Duration of follow up (y) & $20 \cdot 7(3 \cdot 5-29 \cdot 0)$ \\
Person-years of observation 1962-90† & $288886(100)$ \\
Person-years active person-time & $108380(38)$ \\
Person-years inactive person-time & $180506(62)$ \\
\hline
\end{tabular}

${ }^{\star}$ Median (5-95th percentile).

tn $(\%)$. 
Analyses of mortality by smoking habits are not presented as only $18.5 \%$ of the dead could be categorised into ever or never smokers.

Table 3 Observed $(O)$ and expected $(E)$ numbers of deaths from all causes 1962-90 in 14730 employees in 12 Norwegian ferroalloy plants

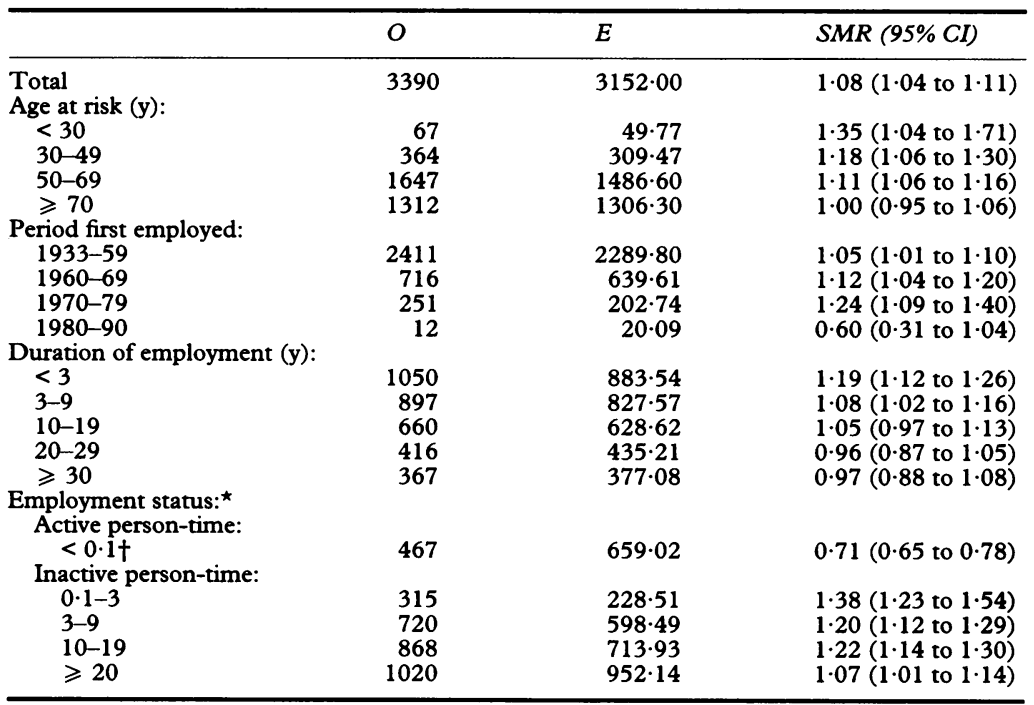

*Years from end of last employment.

†All person-time before end of last employment $+0 \cdot 1$ year.

Table 4 Poisson regression analysis of mortality rates 1962-90 for all causes of death in internal groups of 14730 male employees in 12 Norwegian ferroalloy plants

\begin{tabular}{|c|c|c|c|c|}
\hline Variable & $R R^{*}$ & $(95 \% C I)$ & $\begin{array}{l}\text { Pvalue } \\
(L R T) t\end{array}$ & $\begin{array}{l}\text { Pvalue } \\
\text { (trend) }\end{array}$ \\
\hline \multicolumn{5}{|l|}{ Age (y): } \\
\hline$<30$ & 1.00 & - & - & - \\
\hline $30-49$ & 1.81 & $(1.38$ to 2.37$)$ & - & - \\
\hline $50-59$ & $6 \cdot 21$ & $(4 \cdot 76$ to $8 \cdot 10)$ & - & - \\
\hline $60-69$ & $15 \cdot 40$ & (11.84 to 20.04$)$ & - & - \\
\hline $70-79$ & 33.69 & (25.81 to 43.97$)$ & - & - \\
\hline$\geqslant 80$ & $80 \cdot 86$ & $(61.15$ to 106.9$)$ & 0.00 & - \\
\hline \multicolumn{5}{|c|}{ Time (calendar years): } \\
\hline 1962-9 & $1 \cdot 00$ & - & - & - \\
\hline $1970-9$ & 0.94 & $(0.81$ to 1.09$)$ & - & - \\
\hline $1980-90$ & $0 \cdot 80$ & $(0.68$ to 0.96$)$ & 0.01 & - \\
\hline \multicolumn{5}{|c|}{ Duration of follow up: } \\
\hline$<3$ & 1.00 & - & - & - \\
\hline $3-9$ & $1 \cdot 27$ & (1.06 to 1.52$)$ & - & - \\
\hline $10-19$ & 1.46 & $(1.18$ to 1.80$)$ & - & - \\
\hline$\geqslant 20$ & 1.66 & $(1.32$ to 2.08$)$ & 0.00 & - \\
\hline \multicolumn{5}{|c|}{ Duration of total employment $(y)$ : } \\
\hline$<3$ & 1.00 & - & - & - \\
\hline $3-9$ & 0.96 & $(0.88$ to 1.06$)$ & - & - \\
\hline $10-19$ & 0.94 & $(0.86$ to 1.04$)$ & - & - \\
\hline$\geqslant 20$ & 0.86 & $(0.78$ to 0.95$)$ & 0.03 & 0.00 \\
\hline \multicolumn{5}{|c|}{ Location of the plants: } \\
\hline Rural & 1.00 & - & - & - \\
\hline Urban & $1 \cdot 21$ & $(1 \cdot 13$ to $1 \cdot 29)$ & 0.00 & - \\
\hline
\end{tabular}

${ }^{\star} R R$ adjusted for all other variables.

tLikelihood ratio test (LRT) for withdrawing the variable from the final model.

Goodness of fit statistics for the final model: deviance 309.7, df $311(\mathrm{P}=0.51)$

\section{Results}

The cohort comprised 14730 male workers who were observed for 288886 person-years from 1962 to 1990 (tables 1 and 2). Of the cohort $46 \%$ started employment before the start of follow up, and $20 \%$ of the cohort members were observed only after the end of employment in this industry. Median duration of total employment was 5.4 years and the mean 10.4 years. Median duration of follow up was 20.7 years. Active person-time constituted $38 \%$ of all person-time.

\section{TOTAL MORTALITY}

The SMR for the entire cohort was slightly, but significantly increased with 3390 observed deaths $v 3152$ expected (SMR 1.08, table 3). Excess mortality was found for all categories of age at risk < 70 years, for men first employed before 1980, and for employees with $<10$ years of total employment. The SMR for active person-time was significantly decreased (SMR 0.71) whereas mortality for inactive person-time was significantly increased in all periods. Stratified analyses of total duration of employment by categories of employment status showed almost identical overall mortality for active person-time with SMRs ranging from 0.69 to 0.72 for the categories $<3,3-9$, $10-19$, and $\geqslant 20$ years duration of total employment (not shown).

Total mortality was significantly increased in four of the subcohorts, all located in urban areas (not shown). None of the rural subcohorts showed significantly increased overall SMRs. A Poisson regression analysis of all causes of death with adjustments for age, calendar time, duration of follow up, and duration of employment showed a significantly increased RR for urban areas (RR 1.21) compared with rural areas (table 4). A significant negative trend in the $R R s$ for duration of employment was also found. The mortality for all causes of death for long term work (at least three years) in the different main work areas (departments) were significantly increased only for the FeSi/Si-met and FeMn/SiMn furnace workers (SMR 1.14 in both groups, not shown).

\section{CAUSE SPECIFIC MORTALITY}

Table 5 shows cause specific SMRs for the main causes of death in two categories of duration of employment. For employment dura-

Table 5 Observed $(O)$ and expected $(E)$ numbers of deaths 1962-90 in 14730 male employees in 12 Norwegian ferroalloy plants by duration of total employment

\begin{tabular}{|c|c|c|c|c|c|c|}
\hline \multirow{3}{*}{$\begin{array}{l}\text { Cause of death } \\
\text { (international classification of } \\
\text { diseases, 9th revision (ICD-9)) }\end{array}$} & \multicolumn{6}{|c|}{ Duration of employment } \\
\hline & \multicolumn{3}{|l|}{$<3 y$} & \multicolumn{3}{|l|}{$\geqslant 3 y$} \\
\hline & $O$ & $E$ & $S M R(95 \% C I)$ & $O$ & $E$ & $S M R(95 \% C I)$ \\
\hline $\begin{array}{l}\text { Cancer (140-207) } \\
\text { Circulatory system (390-459) } \\
\text { Respiratory system }(460-519) \\
\text { Digestive system (520-579): } \\
\text { Chronic liver disease, cirrhosis (571) } \\
\text { Sudden death (798) } \\
\text { Accidents, poisonings, violence (800-999): } \\
\text { Suicide (E950-E959) } \\
\text { Alcohol intoxication (E860) } \\
\text { Alcoholism (303) } \\
\text { All other causes } \\
\text { All causes }\end{array}$ & $\begin{array}{r}211 \\
438 \\
55 \\
28 \\
12 \\
55 \\
156 \\
33 \\
11 \\
16 \\
91 \\
1050\end{array}$ & $\begin{array}{r}200 \cdot 89 \\
400 \cdot 11 \\
49 \cdot 08 \\
23 \cdot 82 \\
8 \cdot 63 \\
31 \cdot 76 \\
95 \cdot 69 \\
25 \cdot 76 \\
4 \cdot 40 \\
6 \cdot 20 \\
76 \cdot 11 \\
883.66\end{array}$ & $\begin{array}{l}1.05(0.91 \text { to } 1.20) \\
1.09(0.99 \text { to } 1.20) \\
1.12(0.84 \text { to } 1.46) \\
1.18(0.78 \text { to } 1.70) \\
1.39(0.72 \text { to } 2.43) \\
1.73(1.30 \text { to } 2.25) \\
1.63(1.38 \text { to } 1.91) \\
1.28(0.88 \text { to } 1.80) \\
2.50(1.25 \text { to } 4.48) \\
2.58(1.47 \text { to } 4.19) \\
1.20(0.97 \text { to } 1.47) \\
1.19(1.12 \text { to } 1.26)\end{array}$ & $\begin{array}{r}580 \\
1080 \\
141 \\
64 \\
16 \\
117 \\
171 \\
41 \\
6 \\
16 \\
171 \\
2340\end{array}$ & $\begin{array}{r}523 \cdot 23 \\
1099 \cdot 93 \\
145 \cdot 97 \\
59 \cdot 85 \\
18 \cdot 78 \\
79 \cdot 35 \\
160 \cdot 53 \\
42 \cdot 46 \\
7 \cdot 71 \\
13 \cdot 19 \\
185 \cdot 96 \\
2268 \cdot 01\end{array}$ & $\begin{array}{l}1.11(1.02 \text { to } 1.20) \\
0.98(0.92 \text { to } 1.04) \\
0.97(0.81 \text { to } 1.14) \\
1.07(0.82 \text { to } 1.37) \\
0.85(0.49 \text { to } 1.38) \\
1.47(1.23 \text { to } 1.77) \\
1.07(0.91 \text { to } 1.24) \\
0.97(0.69 \text { to } 1.31) \\
0.78(0.29 \text { to } 1.69) \\
1.21(0.69 \text { to } 1.97) \\
0.92(0.79 \text { to } 1.07) \\
1.03(0.99 \text { to } 1.07)\end{array}$ \\
\hline
\end{tabular}


Table 6 Observed $(O)$ and expected (E) numbers of deaths 1962-90 in 2517 male furnace workers in ferrosilicon and silicon metal production by duration of work

\begin{tabular}{|c|c|c|c|c|c|c|}
\hline \multirow{3}{*}{$\begin{array}{l}\text { Cause of death } \\
\text { (international classification of } \\
\text { diseases, } 9 \text { th revision (ICD-9)) }\end{array}$} & \multicolumn{6}{|c|}{ Duration of work } \\
\hline & \multicolumn{3}{|c|}{$<3 y$} & \multicolumn{3}{|c|}{$\geqslant 3 y$} \\
\hline & $O$ & $E$ & $S M R(95 \% C I)$ & $O$ & $E$ & $\operatorname{SMR}(95 \% C I)$ \\
\hline Cancer (140-207) & 44 & $37 \cdot 75$ & $1.17(0.85$ to 1.56$)$ & 86 & $78 \cdot 22$ & $1 \cdot 10(0.88$ to 1.36$)$ \\
\hline Circulatory system $(390-459)$ & 96 & 74.01 & $1.30(1.05$ to 1.58$)$ & 182 & $164 \cdot 23$ & $1.11(0.96$ to 1.28$)$ \\
\hline Respiratory system (460-519) & 6 & 8.49 & $0.71(0.26$ to 1.54$)$ & 30 & 21.56 & $1.39(0.94$ to 1.99$)$ \\
\hline Digestive system $(520-579)$ : & 10 & $4 \cdot 37$ & $2 \cdot 29(1 \cdot 10$ to $4 \cdot 21)$ & 8 & $8 \cdot 78$ & $0.91(0.39$ to 1.80$)$ \\
\hline Chronic liver, cirrhosis (571) & 6 & 1.63 & $3.68(1.35$ to 8.01$)$ & 2 & $2 \cdot 73$ & $0.73(0.09$ to 2.65$)$ \\
\hline Accidents, poisonings, violence (800-999): & 40 & $17 \cdot 08$ & $2.34(1.67$ to 3.19$)$ & 23 & $22 \cdot 92$ & $1.00(0.64$ to 1.51$)$ \\
\hline Suicide (E950-E959) & 8 & $4 \cdot 71$ & $1.70(0.73$ to 3.34$)$ & 6 & $6 \cdot 13$ & $0.98(0.36$ to 2.13$)$ \\
\hline Alcohol intoxication (E860) & 2 & 0.81 & $2.46(0.30$ to 8.89$)$ & 0 & 1.09 & $0.00(0.00$ to 3.39$)$ \\
\hline Alcoholism (303) & 3 & $1 \cdot 16$ & $2.59(0.53$ to 7.56$)$ & 4 & 1.90 & $2.10(0.57$ to 5.38$)$ \\
\hline
\end{tabular}

Table 7 Observed (O) and expected (E) numbers of deaths 1962-90 in 3086 male furnace workers manufacturing ferromanganese and siliconmanganese by duration of work

\begin{tabular}{|c|c|c|c|c|c|c|}
\hline \multirow{3}{*}{$\begin{array}{l}\text { Cause of death } \\
\text { (international classification of } \\
\text { diseases, 9th revision (ICD-9)) }\end{array}$} & \multicolumn{6}{|c|}{ Duration of work } \\
\hline & \multicolumn{3}{|c|}{$<3 y$} & \multicolumn{3}{|c|}{$\geqslant 3 y$} \\
\hline & $O$ & $E$ & $\operatorname{SMR}(95 \% \mathrm{CI})$ & $O$ & $E$ & $S M R(95 \% C I)$ \\
\hline Cancer $(140-207)$ & 48 & $46 \cdot 83$ & $1.02(0.76$ to 1.36$)$ & 117 & $98 \cdot 44$ & $1.19(0.99$ to 1.42$)$ \\
\hline Circulatory system $(390-459)$ & 101 & $91 \cdot 44$ & $1.10(0.91$ to 1.34$)$ & 214 & $204 \cdot 80$ & $1.04(0.91$ to 1.19$)$ \\
\hline Respiratory system $(460-519)$ & 21 & $10 \cdot 62$ & $1.98(1.22$ to 3.02$)$ & 21 & $26 \cdot 42$ & $0.79(0.49$ to 1.21$)$ \\
\hline Digestive system (520-579): & 9 & $5 \cdot 54$ & $1.63(0.74$ to 3.08$)$ & 18 & $11 \cdot 14$ & $1.62(0.96$ to 2.55$)$ \\
\hline Chronic liver, cirrhosis (571) & 4 & $2 \cdot 12$ & $1.88(0.51$ to 4.82$)$ & 5 & $3 \cdot 56$ & $1.40(0.46$ to $3 \cdot 28)$ \\
\hline Accidents, poisonings, violence (800-999): & 39 & $23 \cdot 26$ & $1 \cdot 68(1.19$ to $2 \cdot 29)$ & 43 & $29 \cdot 89$ & $1.44(1.04$ to 1.94$)$ \\
\hline Suicide (E950-E959) & 9 & $6 \cdot 39$ & $1.41(0.64$ to 2.67$)$ & 11 & $7 \cdot 98$ & $1.38(0.69$ to 2.47$)$ \\
\hline Alcohol intoxication (E860) & 5 & $1 \cdot 11$ & $4.52(1.47$ to 10.5$)$ & 2 & $1 \cdot 45$ & $1.38(0.17$ to 4.98$)$ \\
\hline Alcoholism (303) & 4 & 1.58 & $2.54(0.69$ to 6.50$)$ & 0 & 2.51 & $0.00(0.00$ to 1.47$)$ \\
\hline
\end{tabular}

tion $<3$ years the mortality was significantly increased for all causes (SMR 1·19), sudden death (SMR 1.73), accidents, poisonings, and violence (SMR 1.63), alcohol intoxication (SMR 2.50), and alcoholism (SMR 2.58). For employment duration of three years or more the mortality was significantly increased for deaths from cancer (SMR 1.11), and sudden death (SMR 1.47).

Tables 6 and 7 show the mortality for the main causes of death (without sudden death) among the two groups of furnace workers. For the $\mathrm{FeSi} / \mathrm{Si}$-met furnace workers (table 6) with

Table 8 Poisson regression analysis of mortality rates from accidents, poisonings, and violence in internal groups of 14730 male employees in 12 Norwegian ferroalloy plants observed 1962-90

\begin{tabular}{|c|c|c|c|c|}
\hline Variable/Category & $R R^{\star}$ & $(95 \% C I)$ & $\begin{array}{l}\text { Pvalue } \\
(L R T) t\end{array}$ & $\begin{array}{l}\text { Pvalue } \\
\text { (trend) }\end{array}$ \\
\hline \multicolumn{5}{|l|}{ Age $(y)$ : } \\
\hline$<30$ & $1 \cdot 0$ & - & $\ldots$ & - \\
\hline $30-59$ & $1 \cdot 2$ & $(0.8$ to 1.8$)$ & - & \\
\hline $60-69$ & 1.7 & $(1 \cdot 1$ to $2 \cdot 7)$ & - & $\ldots$ \\
\hline $70-79$ & $1 \cdot 7$ & $(1 \cdot 0$ to $3 \cdot 1)$ & & \\
\hline$\geqslant 80$ & $7 \cdot 1$ & $(3 \cdot 6$ to $14 \cdot 0)$ & $0 \cdot 00$ & - \\
\hline \multicolumn{5}{|c|}{ Time (calendar years): } \\
\hline $1962-9$ & $1 \cdot 0$ & - & - & -.- \\
\hline $1970-9$ & $1 \cdot 2$ & $(0.9$ to 1.6$)$ & & \\
\hline $1980-90$ & $1 \cdot 0$ & $(0.7$ to 1.3$)$ & 0.37 & .... \\
\hline \multicolumn{5}{|c|}{ Employment status: } \\
\hline Active person- $t$ & & & & \\
\hline$<0.1$ & $1 \cdot 0$ & $\ldots .$. & - & - \\
\hline \multicolumn{5}{|c|}{ Inactive person-time: } \\
\hline $0 \cdot 1-3$ & 1.7 & $(1 \cdot 1$ to $2 \cdot 5)$ & $\ldots$ & \\
\hline $3-9$ & 1.7 & $(1 \cdot 2$ to $2 \cdot 4)$ & - & - \\
\hline $10-19$ & 1.6 & $(1 \cdot 1$ to $2 \cdot 4)$ & - & $\ldots$ \\
\hline$\geqslant 20$ & $1 \cdot 1$ & $(0.7$ to 1.7$)$ & 0.002 & .. \\
\hline \multicolumn{5}{|c|}{ Duration of employment $(\mathrm{y})$ : } \\
\hline$<3$ & $1 \cdot 0$ & - & - & $\ldots$ \\
\hline 3-9 & $0 \cdot 7$ & $(0.6$ to 1.0$)$ & - & -.. \\
\hline $10-19$ & 0.7 & $(0.5$ to 1.1$)$ & - & - \\
\hline$\geqslant 20$ & $0 \cdot 6$ & $(0.4$ to 1.0$)$ & 0.08 & 0.05 \\
\hline
\end{tabular}

${ }^{\star} \mathrm{RR}$ adjusted for all other variables.

tLikelihood ratio test (LRT) for withdrawing the variable from the final model.

Goodness of fit statistics for the final model: deviance 193.9, $229 \mathrm{df}(\mathrm{P}=0.96)$. duration of work $<3$ years significantly increased SMRs were found for diseases of the circulatory system (SMR 1.30), diseases of the digestive system (SMR 2.29), and accidents, poisonings, and violence (SMR 2.34). For the category with $\geqslant 3$ years duration of work at the $\mathrm{FeSi} / \mathrm{Si}$-met furnaces none of the SMRs were significantly increased.

Among FeMn/SiMn furnace workers (table 7) with $<3$ years duration of work excess deaths were found from diseases of the respiratory system (SMR 1.98), accidents, poisonings, and violence (SMR 1.68), and alcohol intoxication (SMR 4.52). The FeMn/SiMn furnace workers with $\geqslant 3$ years duration of work showed significantly increased SMRs for accidents, poisonings, and violence (SMR 1.44).

MORTALITY FROM ACCIDENTS, POISONINGS, AND VIOLENCE

The mortality from accidents, poisonings, and violence among all employees was significantly increased (SMR 1.28). Further analysis showed decreasing SMRs by increasing duration of employment. Analysis of mortality from this cause by employment status was also performed. The SMR for active person-time was not increased (SMR 0.90, 83 deaths). The SMRs for inactive person-time covering the first 20 years after the end of employment were all significantly increased (range of SMRs 1.58-1.69). The mortality from this cause was further studied with a Poisson regression analysis (table 8). A significant negative trend $(P=0.05)$ in the RRs with increasing duration of employment was found. The situation of the plants (rural or urban) was not a significant variable in this model and was therefore not included. 


\section{Discussion}

The mortality for all causes of death in the entire cohort was slightly but significantly increased (SMR 1.08). This result is in contrast with results from the previous Norwegian studies of mortality and cancer incidence among employees in seven ferroalloy plants ${ }^{1-3}$ where overall SMRs lower than expected were found. A mortality study in a Swedish $\mathrm{FeCr}$ plant ${ }^{19}$ also found a smaller than expected overall mortality but an increased mortality from cancer among maintenance workers. This was also found among workers producing $\mathrm{FeCr}$ and stainless steel in France ${ }^{20}$ where a significant excess of lung cancer was found among exposed workers.

\section{ASSOCIATION WITH DURATION OF WORK OR EMPLOYMENT}

For overall mortality and most of the various main causes of death the SMRs were lowest in the categories with longest duration of employment. Internal comparisons of overall mortality (table 4) showed a significant negative trend with increasing duration of employment, and total mortality was not positively associated with duration of work in any of the various main groups of workers. Regarding the specific causes of death the mortality results for cancer and sudden death among all employees (table 5) could indicate a relation with work exposures. Separate studies of cancer incidence and mortality from sudden death are therefore planned.

It seems probable that most deaths from accidents, poisonings, and violence will occur immediately or shortly after the actual events. Due to the SMR of 0.90 for active person-time there seems to be no association between employment and this cause of death. The risk of experiencing a fatal accident, poisoning, or violence has thereby increased after the end of employment in this industry (SMR for inactive person-time 1.49).

\section{VALIDITY ASPECTS}

An increased overall mortality was found among short term workers (SMR 1.19) but not among long term workers (SMR 1.03). Also, the highest SMRs for deaths from accidents, poisonings, violence, alcohol intoxication, and alcoholism were found in the subgroup of short term workers. These results indicate different influences of lifestyle factors (different alcohol consumption) among short and long term workers. Higher mortalities from all and some specific causes of death among short term workers compared with long term workers have also been reported from other studies ${ }^{21-22}$ and are supposed to be due to lifestyle factors. This effect may be more pronounced in our study, however, as a distinction between short and long term employment has been made at three years of employment and not at one year as in both the other studies. ${ }^{21-22}$

Some of our results suggest that a change in lifestyle factors may have occurred from active to inactive person-time. Mortality from alcohol intoxication was significantly increased among short term workers (SMR 2.50 for all person-time), but the SMR for active persontime was, however, zero and all the 11 deaths occurred during inactive person-time (SMR $2 \cdot 79$, not shown). The mortality from accidents, poisonings, and violence was also increased only for inactive person-time, which might be related to a higher consumption of alcohol during inactive than during active person-time. Another result with an uncertain relation to lifestyle factors with regard to mortality from suicide was not increased during active person-time (SMR 0.66), but increased for the periods < 3 years (SMR 1.88) and 3-9 years (SMR 1.89) after last employment. Our data give no information about further employment after leaving the ferroalloy industry. However, the results could be associated with unemployment during inactive persontime. In a Finnish study of unemployment and mortality ${ }^{23}$ similar results were found, with a relative mortality from accidental and violent causes of death of 2.51 and from alcohol poisonings of 4.62 (unemployed $v$ employed).

The different recruitment and observation periods probably introduce a selection bias. The recruitment period started 29 years before the observation period (1933 and 1962, respectively), and $20 \%$ of the cohort members were followed up only during inactive persontime. A higher mortality for inactive than active person-time has been found at least for age at risk $<70$ years. We therefore suppose that a lower overall mortality would have been found if the recruitment and observation periods were identical.

Individual information about lifestyle factors other than smoking are lacking in this study. Age adjusted comparisons of smoking habits with the total Norwegian male population $^{24}$ for the years 1989-90 were performed for those still employed in most of the plants. The comparisons showed a $10 \%-20 \%$ higher level of current smokers among employees $<50$ years old than in the corresponding male Norwegian population. Among men of 50 or older differences in smoking habits were smaller or negligible, indicating a higher turnover of smokers than non-smokers in the workforce or changes in smoking habits with year of birth. The results of-for example, respiratory system diseases and sudden deathmay therefore be confounded by smoking.

\section{Conclusions}

In summary, a slight but significantly increased SMR for all causes of death (SMR 1.08) was found among 14730 male employees in 12 Norwegian ferroalloy plants. Significantly increased mortalities from cancer (SMR 1.11) and sudden death (SMR 1.47) were found among employees with at least three years duration of employment. These results could be related to work exposures, at least in certain subgroups, and warrant further studies. Excess deaths from accidents, poisonings, and violence were found among all employees (SMR 1.28). The mortality from this cause was however not increased during 
the employment period (SMR for active person-time 0.90 ) and is probably not related to work exposures. The increased mortality among short term workers, and other information suggest that systematic errors contribute to the increased overall mortality.

This project has been supported by grants from the Work Environment Fund of the Confederation of Norwegian Business and Industry (NHO) and from the Norwegian Research Council for Science and Humanities. We are grateful to Aage Andersen, Tor Haldorsen, and Oddvar Sandvin at the to Aage Andersen, Tor Haldorsen, and Oddvar Sandvin at the
Norwegian Cancer Registry for help with identification prob-
lems and linking of the cohort, for statistical advice, and for lems and linking of the cohort, for statistical advice, and for assistance on the epicure software, respectively, and to Ole Secretariat for the Norwegian Smelters for his assistance in the cooperation with participating plants and the financial support.

1 Langård S, Andersen A, Gylseth B. Incidence of cancer among ferrochromium and ferrosilicon workers. $\mathrm{Br} \mathcal{F}$ Ind Med 1980;37:114-20.

2 Langård S, Andersen A, Ravnestad J. Incidence of cancer among ferrochromium and ferrosilicon workers: an extended obervation period. $B r \mathcal{F}$ Ind Med 1990;47:14-9.

3 Kjuus $\mathrm{H}$, Andersen A, Langárd S, Knudsen KE. Cancer incidence among workers in the Norwegian ferroalloy industry. $\mathrm{Br} F$ Ind $\mathrm{Med}$ 1986;43:227-36.

4 Balaan MR, Banks DE. Silicosis. In: Rom WN, ed. Environmental and occupational medicine. Boston/Toronto/ London: Little Brown, 1992:345-58.

5 Silica and some silicates. LARC Monogr Eval Carcinog Risks Hum 1987;42:108-11.

6 Pairon JC, Brochard P, Jaurand MC, Bignon J. Silica and lung cancer: a controversial issue. Eur Respir 7 1991;4: $730-44$

7 Roels H, Lauwerys R, Buchet JP, Genet P, Sarhan MJ, Hanotiau I, de Fays $M$, et al. Epidemiological survey among workers exposed to manganese: effects on lung central nervous system, and some biological indices. $A m \mathcal{F}$ Ind Med 1987;11:307-27.

8 Bergström R. Acute pulmonary toxicity of manganese dioxide. Scand F Work Environ Health 1977;3(suppl 1):1-41.
9 Koskela RS. Cardiovascular diseases among foundry workers exposed to carbon monoxide. Scand $\mathcal{\exists}$ Work Environ Health 1994;20:286-93.

10 Stern FB, Halperin WE, Hornung RW, Ringenburg VL McCammon CS. Heart disease mortality among bridge and tunnel officers exposed to carbon monoxide. $A m$ Epidemiol 1988;128:1276-88.

11 Polynuclear aromatic compounds, part 3, industrial exposures in aluminium production, coal gasification, coke production, and iron and steel founding. LARC Monogr Eval Carcinog Risks Hum 1984;34:181-3.

12 Bonassi S, Merlo F, Pearce N, Puntoni R. Bladder cancer and occupational exposure to polycyclic aromatic hydrocarbons. Int $\mathcal{F}$ Cancer 1989;44:648-51.

13 Kristensen TS. Cardiovascular diseases and the work environment. A critical review of the epidemiologic literature on chemical factors. Scand $\mathcal{F}$ Work Environ Health 1989 ; 15:245-64.

14 Mossmann BT, Gee JBL. Asbestos-related diseases. N Eng f Med 1989;320:1721-30.

15 Preston DI, Lubin JH, Pierce DA, McConney ME. Epicure. Seattle, Washington: Hirosoft International, 1993.

16 Steenland K, Stayner L. The importance of employment status in occupational cohort mortality studies. Epidemiology 1991;2:418-23.

17 Breslow NE, Day NE. Statistical methods in cancer research, vol ii-the design and analysis of cohor studies. Lyon,

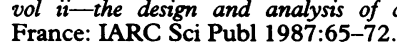

18 Pearce N. Methodological problems of time-related variables in occupational cohort studies. Rev Epidemiol Sante Publique 1992;40:43-54.

9 Axelsson G, Rylander R, Schmidt A. Mortality and incidence of tumours among ferrochromium workers. $\mathrm{Br} f$ Ind Med 1980;37:121-7.

20 Moulin J, Portefaix P, Wild P, Mur JM, Smagghe G, Mantout B. Mortality study among workers producing ferroalloys and stainless steel in France. Br $\mathfrak{f}$ Ind Med 1990;47:537-43.

21 Gubéran E, Usel $M$. Unusual mortality pattern among short term workers in the perfumery industry in Geneva. $\mathrm{Br}$ F Ind Med 1987;44:595-601.

22 Stewart PA, Schairer C, Blair A. Comparison of jobs, exposures, and mortality risks for short-term and long-term workers. $\mathcal{F}$ Occup Med 1990;32:703-8

23 Martikainen PT. Unemployment and mortality among Finnish men, 1981-5. BMF 1990;301:407-11.

24 Rønneberg A, Lund KE, Hafstad A. Lifetime smoking habits among Norwegian men and women born between 1890 and 1974. Int भ Epidemiol 1994;23:267-76.

\section{Instructions to authors}

Three copies of all submissions should be sent to: The Editor, Occupational and Environmental Medicine, BMJ Publishing Group, BMA House, Tavistock Square, London WC1H 9JR, UK. All authors should sign the covering letter as evidence of consent to publication. Papers reporting results of studies on human subjects must be accompanied by a statement that the subjects gave written, informed consent and by evidence of approval from the appropriate ethics committee. These papers should conform to the principles outlined in the Declaration of Helsinki (BMF 1964; ii:177).
If requested, authors shall produce the data on which the manuscript is based, for examination by the Editor.

Authors are asked to submit with their manuscript the names and addresses of three people who they consider would be suitable independent reviewers. They will not necessarily be approached to review the paper.

Papers should include a structured abstract of not more than 300 words, under headings of Objectives, Methods, Results, and Conclusions. Please include up to three keywords or key terms to assist with indexing. 